\title{
Modelling Firm Innovation using Panel Probit Estimators*
}

\author{
Mark N. Harris \\ Melbourne Institute and Central European University, Hungary. \\ Mark Rogers \\ Harris Manchester College, Oxford University, U.K. \\ Anthony Siouclis \\ Monash University, Melbourne, Australia \\ Melbourne Institute of Applied Economic and Social Research, \\ University of Melbourne, Vic. 3010, Australia \\ Telephone: (03) 83443701 \\ Fax: (03) 83445630 \\ Email: melb.inst@iaesr.unimelb.edu.au \\ WWW Address: http://www.melbourneinstitute.com \\ Melbourne Institute Working Paper No. 20/01 \\ ISSN 1328-4991 \\ ISBN 0734015240
}

\footnotetext{
* This paper is the result of work being undertaken as part of a collaborative research program entitled "The Performance of Australian Enterprises: Innovation, Productivity and Profitability". The project is generously supported by the Australian Research Council and the following collaborative partners: ATO, Commonwealth Office of Small Business, IBIS Business Information Pty Ltd, Productivity Commission
} 


\begin{abstract}
Firm-level innovation is investigated using three probit panel estimators, which control for unobserved heterogeneity, and a standard probit estimator. Results indicate the standard probit model is misspecified and that inter-firm networks are important for innovation.
\end{abstract}

and Victorian Department of State Development. The views expressed in this paper represent those of the authors and not the views of the collaborative partners. 


\section{Introduction}

This paper models a firm's innovative status using Australian survey data (1996 to 1998) for 3,757 firms. The survey asked each firm whether it had made an innovation - defined as any new of substantially improved product, service or process - during the last year. This binary measure allows a probit model to be estimated.

Previous empirical studies have investigated a wide range of potential factors that might be linked to a firm's propensity to innovate Symeonidis (1996). The data available allow an investigation into the role of firm size, past profitability, the presence of a formal business plan, the incidence of any export activity, R\&D and the role of inter-firm networks. The role of inter-firm networks, although considered by many as an important aspect, has received little analysis due to the paucity of data. The prior work on networks, which reflects the general body of empirical evidence, tends to be based on cross sectional data, where these data are often from surveys with low response rates (Karlsson and Olsson (1998) and Love and Roper (1999)). In contrast, the data used here represent a panel and come from a survey with very high response rate. ${ }^{1}$

The focus of the paper is two fold. First, to investigate the importance of the above mentioned characteristics in a unique and large set of data. Second, to provide a comparison of different estimators, especially with respect to panel estimators. As a baseline, the standard cross section binary probit model is estimated (this ignores any potential firm unobserved heterogeneity). The remaining three methods all account for (potential) unobserved heterogeneity. The first of these is "classical" maximum likelihood estimation of the model using Gaussian quadrature methods (MLQ), whilst the second uses the Solomon-Cox (SC) approximation of the likelihood function. Finally, the Gibbs sampler is used to obtain Bayesian estimates which circumvent the need for evaluating the likelihood function.

\section{Binary Panel Probit Models}

If panel data are available, then, in general, one can relatively easily condition on the unobserved as well as the observed heterogeneity that is likely to be present in the data

\footnotetext{
${ }^{1}$ It was conducted by the Australia Bureau of Statistics who require a response under law.
} 
Matyas and Sevestre (1996). For example, in the case of firm level data, unobserved heterogeneity could reflect management ability or strategy.

The binary probit model for innovative status can be written as

$$
y_{i t}^{*}=x_{i t}^{\prime} \beta+\alpha_{i}+v_{i t}, i=1, \ldots, N, t=1, \ldots, T,
$$

where $\alpha_{i}$ are the unobserved effects and $x_{i t}^{\prime}$ is a set of explanatory variables and $v_{i t}$ is the usual error term. However, the latent variable, the propensity to innovate $y_{i t}^{*}$, is not observed. What is observed is the realisation of this (simply whether innovation occurred or not) such that

$$
y_{i t}=\left\{\begin{array}{l}
1 \text { if } y_{i t}^{*}>0 \\
0 \text { if } y_{i t}^{*} \leq 0
\end{array} .\right.
$$

On the assumption that the $\alpha_{i}$ are stochastic, there are various methods of estimating 2.1. This paper considers three. First, maximum likelihood estimation is computationally intensive unless one assumes that $\alpha_{i}$ and $v_{i t}$ are independent. Now the correlation across $i$ is constant such that

$$
\operatorname{Corr}\left(\varepsilon_{i t}, \varepsilon_{i s}\right)=\rho=\sigma_{\alpha}^{2} /\left(\sigma_{\alpha}^{2}+\sigma_{v}^{2}\right), \varepsilon_{i t}=\alpha_{i}+v_{i t}, t \neq s .
$$

The estimation problem is now simplified to a single integral, which can be evaluated using Gaussian quadrature Butler and Moffitt (1982).

Second, the Solomon-Cox (SC) approximation is a general estimation technique which can be used to provide an analytical solution for maximum likelihood estimation of nonlinear panel data models with random effects, the likelihoods of which are often very complex, or indeed, intractable. The SC approximation applied to the binary panel probit model with random effects again assumes that the $\alpha_{i}$ are independently normally distributed for all $i$. Full details are contained in Lieberman and Matyas (1996).

Third, the final estimation method used is the Gibbs sampler (a Monte Carlo Markov Chain method of sampling, well suited to Bayesian inference). This method of estimation has simplified the Bayesian analysis of panel data models providing precise finite sample estimates. The Gibbs sampling algorithm simulates the posterior distribution rather than computing the posterior moments, and may be a preferred estimation tool over its likelihood based counterparts (see Albert and Chib (1993) and Albert and Chib (1995)). 


\section{Empirical Model and Data}

The data available contains an innovation status variable $(0=$ no innovation, $1=$ innovation) that measures whether the firm has made an innovation in the last year. Where 'innovation' is defined as the introduction of any new, or substantially improved, product, process or service. Innovation status is therefore the binary dependent variable. The data are taken from the Confidentialised Unit Record File for the Business Longitudinal Survey of Australian firms (see Rogers (1998) for more details). Only firms with less than 200 employees are available. Although 4 years of data are in the data file (1995 - 1998), only the last three years of data are used due to the non-availability of key variables in 1995 . This leaves a working panel of the dimensions, $N=3,757$ and $T=3$.

Previous literature has investigated a wide range of potential covariates with regard to innovation status. Empirical work has suggested it is important to control for firm size Arvanitis (1997), foreign ownership Rogers (1999), export activity Lefebvre, Lefebvre, and Bourgault (1998), past cash flow and profitability and market structure (see Symeonidis (1996) for a summary of these and other issues). This set of variables is augmented by variables on the use of business planning and formal networking by the firms (each variable is a binary 'yes/no' that defines whether the firm has used these methods in the past year). The networking variable is of particular interest since there is considerable theoretical and policy interest in how networks between firms, or clusters, affect innovation. To date there are limited empirical studies on this issue (Love and Roper (1999), find a positive influence of networking, Karlsson and Olsson (1998), find no association).

The set of explanatory variables, therefore, includes dummy variables for networking, business planning, export activity, R\&D activity (equal to if any $R \& D$ expenditure is reported) and whether the firm is a start-up (equal to 1 if firm less than two years old in 1995). Continuous variables for the number of effective full time employees and the lagged profit margin (net profit before tax over revenue) are also included.

Summary statistics of the data used are presented in Table 3.1. The data show that innovation occurs infrequently, for example, of the 11, 271 observations only 2,629 (23.3\%) report an innovation. Considering each firm separately, of the 3,757 firms there are 237 firms $(6.3 \%)$ who reported an innovation in each of the three years of data. These firms represent high innovation companies and account for 711 observations in the data. In 
Table 3.1: Variable Means

\begin{tabular}{lccc}
\hline Variable & Full sample & $\begin{array}{c}\text { High innovators } \\
(n=711)\end{array}$ & $\begin{array}{c}\text { No innovations } \\
(n=6,303)\end{array}$ \\
\hline Innovative status & 0.23 & 1 & 0 \\
$\log ($ full time employees) & 2.44 & 3.17 & 2.16 \\
Profit margin & 0.06 & 0.05 & 0.07 \\
Business plan & 0.33 & 0.61 & 0.24 \\
Network & 0.23 & 0.39 & 0.16 \\
Export status & 0.22 & 0.42 & 0.15 \\
Start up firm & 0.07 & 0.04 & 0.07 \\
R\&D active & 0.11 & 0.46 & 0.03 \\
\hline
\end{tabular}

contrast, the no innovation firms $(2,101)$ represent 6,303 observations. Moreover, Table 3.1 shows that high innovation companies are considerably larger (the mean size of the high innovators is almost 41 employees, while the no innovators mean is 21 full time employees). There are also considerable differences in the R\&D, network and business plan dummy variables, across firms.

\section{Results and Evaluation}

The various estimation results are presented in Table 4.1. The first column reports the CS probit model which has $\alpha_{i}=\alpha \forall i$ ). The subsequent columns report the results from the three different panel probit estimators discussed above. ${ }^{2}$ These results show that the four procedures yield similar parameter estimates, especially across the MLQ and Gibbs methods (and to a lesser extent, the SC one). However, all of the three panel estimators differ from the standard probit model (i.e. allowing for unobserved heterogeneity appears important). More specifically, the coefficients from the panel estimators are generally higher than the standard probit model. Tests for unobserved heterogeneity can be based

\footnotetext{
${ }^{2}$ Gauss code for the empirical example is available on request from the authors. The code for the Gibbs sampler, was kindly provided by S. Chib.
} 
upon the significance of the estimate of $\rho$. In all cases unobserved heterogeneity was detected giving credence to the hypothesis that CS probit model is misspecified.

From an economic perspective the results are interesting for a number of reasons. First, the positive coefficient on employees, a proxy for firm size, indicates that larger firms are more likely to innovate. While this may reflect the nature of the survey question (i.e., innovation status does not reflect innovation intensity, hence larger firms may be over represented even though intensity of innovation is similar), it is also compatible with the idea of economies of scale in innovative activity. Export activity and whether the firm is a 'start-up' have no significant association with innovative status. Equally, there is no significant association with past profitability. This is reassuring in that it implies firms do not have to rely on past profits to finance innovation (i.e. the capital market appears to be acting to remove any such constraint. As expected, the presence of business planning has a significant positive association with innovative status. Similarly, R\&D activity has a positive association. Both of these variables can be regarded as 'control' variables in the sense that they are closely linked to the innovation process. Lastly, the networking variable shows a significant positive association across all estimators. This is an important result in that it supports many policy statements concerning the benefits of encouraging formal networking between firms.

\section{Conclusion}

The results of the analysis indicate that large firms (as proxied by the number of employees) are more likely to innovate, although past profitability (proxied by last year's profit to revenue ratio) has no association. Firms that have a formal business plan, or formal networks with other firms, or R\&D expenditure also more likely to report an innovation. The analysis shows that these factors tend to have stronger effects when (unobserved) firm heterogeneity is controlled for, suggesting that these aspects matter in themselves and are not simply proxies for unobservable characteristics (for example management quality or organisation culture). This result highlights the other contribution of the paper in comparing panel probit estimators. The results find that unobserved heterogeneity is present which suggests that the CS probit model is misspecified. Of the three panel probit estimators, the parameter estimates indicate that there is little to differentiate between 
Table 4.1: Parameter Estimates $(\mathrm{N}=3,757, \mathrm{~T}=3)^{a, b, *}$

\begin{tabular}{lcccc}
\hline Variable & CS Probit & MLQ & SC & Gibbs \\
\hline \hline Constant & -1.293 & -1.646 & -1.521 & -1.646 \\
& $(0.032)^{*}$ & $(0.052)^{*}$ & $(0.048)^{*}$ & $(0.052)^{*}$ \\
Effective full-time employees & 0.055 & 0.075 & 0.067 & 0.075 \\
& $(0.012)^{*}$ & $(0.017)^{*}$ & $(0.014)^{*}$ & $(0.017)^{*}$ \\
Lagged profit margin & -0.039 & -0.063 & -0.051 & -0.073 \\
& $(0.047)$ & $(0.056)$ & $(0.063)$ & $(0.056)$ \\
Business plan $\times 1$ & 0.399 & 0.485 & 0.454 & 0.485 \\
Network $\times 1$ & $(0.031)^{*}$ & $(0.042)^{*}$ & $(0.035)^{*}$ & $(0.042)^{*}$ \\
& 0.329 & 0.410 & 0.380 & 0.409 \\
Export $\times 1$ & $(0.033)^{*}$ & $(0.044)^{*}$ & $(0.038)^{*}$ & $(0.043)^{*}$ \\
& 0.041 & 0.072 & 0.062 & 0.071 \\
Start-up firm $\times 1$ & $(0.036)^{*}$ & $(0.050)$ & $(0.041)$ & $(0.051)$ \\
\multirow{2}{*}{ R\&D $\times 1$} & -0.015 & 0.005 & -0.004 & 0.001 \\
& $(0.055)$ & $(0.081)$ & $(0.069)$ & $(0.082)$ \\
$\rho$ & 1.313 & 1.613 & 1.502 & 1.613 \\
& $(0.044)^{*}$ & $(0.061)^{*}$ & $(0.053)^{*}$ & $(0.063)^{*}$ \\
Max. log-likelihood & - & 0.380 & 0.353 & 0.381 \\
\hline & $-5,166$ & $-4,983$ & $-5,055$ & - \\
\hline
\end{tabular}

${ }^{a}$ Robust standard errors in parentheses.

${ }^{b}$ Standard deviation of the posterior distribution.

*Significant at $5 \%$ 
the alternative methods.

\section{References}

Albert, J., And S. Chib (1993): "Bayesian Analysis of Binary and Polychotomous Response Data," Journal of the American Statistical Association, 88, 669-679.

(1995): "Bayesian Residual Analysis for Binary Response Regression Models," Biometrika, 82, 747-759.

Arvanitis, S. (1997): "The Impact of Firm Size on Innovative Activity - An Empirical Analysis Based on Swiss Firm Data," Small Business Economics, 9, 473-490.

Butler, J., And R. Moffitt (1982): "A Computationally Efficient Quadrature Procedure for the One Factor Multinomial Probit Model," Econometrica, 50(3), 761-764.

Karlsson, C., And O. Olsson (1998): "Product Innovation in Small and Large Enterprises," Small Business Economics, 10, 31-46.

Lefebvre, E., L. Lefebvre, and M. Bourgault (1998): "Research and DevelopmentRelated Capabilities as Determinants of Export Performance," Small Business Economics, 10, 365-377.

Lieberman, O., and L. Matyas (1996): Improved Estimation Procedureschap. 21, pp. 573-582. Kluwer Academic Publishers, The Netherlands, 2nd edn.

Love, J., And S. Roper (1999): "The Determinants of Innovation: Research and Development, Technology Transfer and Networking Effects," Review of Industrial Organisation, 15, 43-64.

Matyas, L., And P. Sevestre (1996): The Econometrics of Panel Data. Kluwer Academic Publishers, The Netherlands.

Rogers, M. (1998): "Innovation in Australian Enterprises: Evidence from the GAPS and IBIS Databases," Discussion Paper 19/98, Melbourne Institute, University of Melbourne. 
(1999): "Innovation in Australian Workplaces: An Empirical Analysis," Australian Bulletin of Labour, 25(4), 334-351.

Symeonidis, G. (1996): "Innovation, Firm Size and Market Structure: Schumpeterian Hypotheses and Some New Themes," OECD Economics Dept. Working Paper, 161. 